Artículo

\title{
Ácaros fitófagos asociados a jitomate en el norte de Sinaloa, México
}

\author{
Manuel Ángel Lugo-Sánchez ${ }^{1}$ \\ Ricardo Javier Flores-Canales ${ }^{2}$ \\ Néstor Isiordia-Aquino ${ }^{3}$ \\ Gabriel Antonio Lugo-García ${ }^{3 \S}$ \\ Álvaro Reyes-Olivas ${ }^{3}$ \\ ${ }^{1}$ Posgrado en Ciencias Biológico Agropecuarias-Universidad Autónoma de Nayarit. Carretera Tepic- \\ Compostela km 9, Xalisco, Nayarit, México. CP. 63780. Tel. 687 1819975. (mals_23@ hotmail.com). \\ ${ }^{2}$ Unidad Académica de Agricultura-Universidad Autónoma de Nayarit. Carretera Tepic-Compostela km 9, \\ Xalisco, Nayarit, México. CP. 63780. Tel. 311 1184365. (ricardo_flores_uan@ @otmail.com). ${ }^{3}$ Colegio de \\ Ciencias Agropecuarias-Universidad Autónoma de Sinaloa. Calle 16 y Avenida Japaraqui, Juan José Ríos, \\ Ahome, Sinaloa, México. CP. 81110. Tel. 668 1025140. (nisiordia@ gmail.com). \\ §Autor para correspondencia: gabriel_lugo9010@hotmail.com.
}

\section{Resumen}

Debido a la gran importancia que tiene Sinaloa en la producción de jitomate rojo en México, surgió la necesidad de realizar la presente investigación cuyo objetivo fue determinar las especies de ácaros fitófagos asociados al cultivo de jitomate en el norte de Sinaloa y conocer su fluctuación poblacional. El trabajo se realizó en el norte del estado, en cuatro sitios de muestreo y dos sistemas de producción (malla sombra y campo abierto). Los muestreos se realizaron en una periodicidad quincenal durante el periodo de diciembre de 2015 a mayo de 2016, aleatoriamente se seleccionaron 10 plantas por parcela y se consideraron 30 foliolos por planta, 10 por estrato (superior, medio e inferior) como unidad de muestreo. Se recolectaron 1548 ácaros en malla sombra y 1314 en campo abierto, del total de ácaros recolectados, $71.5 \%$ correspondió a Tetranychus urticae, $13.2 \%$ a Polyphagotarsonemus latus y $15.3 \%$ a Phytonemus pallidus. La especie T. urticae estuvo presente durante todas las etapas de desarrollo del cultivo, su fluctuación poblacional osciló conforme a las condiciones de temperatura, con menores registros de presencia durante enero-febrero y mayor incidencia durante abril-mayo. La presencia del ácaro ciclamen, $P$. pallidus en sistema de producción malla sombra durante la etapa reproductiva del cultivo representa el primer registro de presencia de esta especie sobre el cultivo en el norte de Sinaloa.

Palabras clave: Phytonemus pallidus, Polyphagotarsonemus latus y Tetranychus urticae, malla sombra.

Recibido: julio de 2019

Aceptado: septiembre de 2019 


\section{Introducción}

El jitomate rojo mexicano Solanum lycopersicum L. (Solanaceae) es la hortaliza que genera más divisas en México, con una participación en el mercado internacional de $21 \%$ del valor de las exportaciones mundiales (SAGARPA, 2014). Estadísticas proporcionadas por el Servicio de Información Agroalimentaria y Pesquera (SIAP, 2016), reflejan que en México se destinan 51000 ha a la producción de jitomate, con una producción de 2.8 millones de toneladas, de las cuales 15 307 t se establecieron en Sinaloa, con una producción de 867164 t anuales, que equivale a $20 \%$ del volumen producido en la totalidad del país: esto coloca a Sinaloa como el principal productor de jitomate de exportación.

El $100 \%$ de la superficie de Sinaloa se siembra de riego y es afectado por insectos, ácaros y enfermedades que disminuyen el rendimiento de los cultivos (Sánchez-Peña et al., 2006). En México los agricultores enfrentan serios problemas fitosanitarios que ocasionan pérdidas económicas, entre los que destacan las enfermedades causadas por virus, hongos y bacterias (Jaramillo et al., 2007), así como de insectos y ácaros (Nuño-Moreno, 2007).

Existe una gran diversidad de plagas que afectan la producción de jitomate como la mosca blanca (Bemisia argentifolii Bellows \& Perring), el minador de la hoja (Liriomyza trifolii Burgess), el pulgón verde del melocotonero (Myzus persicae Sulzer), la paratrioza (Bactericera cockerelli Sulc), el trips de las flores (Frankliniella occidentalis Pergande), gusano alfiler (Keiferia lycopersicella Walsingham), la araña roja (Tetranychus urticae Koch), y el ácaro tostado del jitomate (Aculops lycopersici Massee), entre otros. T. urticae y A. lycopersici causan severos daños a muchos cultivos en las hojas y los frutos, de manera que las áreas lesionadas se decoloran y los bordes de las hojas presentan deformaciones como consecuencia de la extracción de savia de los tejidos que influye en el crecimiento, defoliación, decoloración, disminución en la producción y por último la muerte de la planta (Fasulo, 2000).

Los daños por ácaros en todo tipo de cultivos se incrementaron de forma progresiva, al pasar de ser plagas secundarias a plagas primarias en la agricultura (Jeppson et al., 1975). A nivel mundial, estos artrópodos están representados 109 familias (Zhang, 2011) y 54617 especies, de las cuales 2 625 se encuentran presentes en México, distribuidas en cinco órdenes, lo que representa $4.8 \%$ de la riqueza mundial (Pérez et al., 2013), ubicadas en las familias Eriophyidae, Tetranychidae, Tenuipalpidae y Tarsonemidae, que incluyen especies de importancia agrícola (Evans, 1992), en el caso particular de Tetranychidae, esta familia se encuentra constituida por 1200 especies agruparas en 70 géneros, dentro de los cuales, las especies pertenecientes a Tetranychus son las que producen las mayores pérdidas a la agricultura (Zhang, 2003).

En Sinaloa están registradas 135 especies de ácaros, número muy bajo para la enorme cantidad que debe existir en los distintos hábitats terrestres y acuáticos del estado; pero, se carece de un estudio sistemático de la acarofauna en la entidad, ya que sólo se tienen datos esporádicos y casuales de ciertas especies de importancia médica y veterinaria (Hoffmann et al., 2000). Por lo tanto, el objetivo del presente estudio fue determinar las especies de ácaros asociadas al cultivo de jitomate en el norte de Sinaloa y conocer su fluctuación poblacional. 


\section{Materiales y métodos}

El estudio se realizó en cuatro sitios de muestreo: Agrícola Los Reyes (25 $78^{\prime} 34^{\prime \prime}$ latitud norte, $108^{\circ} 88^{\prime} 42^{\prime \prime}$ longitud oeste), Agrícola San José (2581' 54" latitud norte, $108^{\circ} 75^{\prime}$ '58" longitud oeste), Agrícola Moreno ( $25^{\circ} 71^{\prime} 23^{\prime}$ ' latitud norte, $108^{\circ} 67^{\prime} 39^{\prime \prime}$ longitud oeste) y Agrícola Meza ( $25^{\circ} 74^{\prime} 10^{\prime \prime}$ latitud norte, $108^{\circ} 82^{\prime}$ '83" longitud oeste), ubicados en los municipios de Ahome y Guasave, en el norte de Sinaloa. Para los dos primeros sitios, el sistema de producción fue en campo abierto, mientras que en los otros sitios fue en malla sombra.

Con una frecuencia quincenal, los muestreos se realizaron durante el periodo comprendido entre los días 20 de diciembre de 2015 al 25 de mayo de 2016. En cada parcela se realizaron transectos lineales diagonales, sobre los cuales se tomaron las muestras del ácaro aleatoriamente (Bautista $e t$ $a l .$, 2004). Con el propósito de precisar la ubicación de las especies, se seleccionaron 10 plantas por parcela aleatoriamente, 10 foliolos de cada estrato de la planta (superior, medio e inferior) (Rabinovich, 1980).

Los foliolos se depositaron en bolsas de polietileno de $30 \times 25 \mathrm{~cm}$, se etiquetaron e introducidos en una hielera para su conservación, se trasladaron al Laboratorio de Entomología de la Facultad de Agricultura del Valle del Fuerte, de la Universidad Autónoma de Sinaloa. Las hojas recolectadas se revisaron en un microscopio estereoscópico marca LBM Luxeo 4Z. Los ácaros de cada muestra se depositaron en un frasco vial con alcohol al $70 \%$ con un pincel; para el montaje, los ácaros se aclararon en ácido láctico conforme a la metodología de Krantz y Walter (2009).

Las laminillas secas se depositaron en estuches entomológicos y se identificaron conforme a las claves taxonómicas de Tuttle et al. (1974); Jeppson et al. (1975); Krantz (1978). La corroboración de especies la realizó el Dr. Gabriel Otero Colina, del Colegio de Postgraduados Campus Montecillo. Las imágenes ácaros adultos fueron tomadas con un microscopio Carl Zeiss Tessovar y posteriormente fueron tratadas con el software Gimp versión 2.8.14, para poder realizar los dibujos. El efecto de los factores como precipitación y temperaturas sobre la densidad poblacional de los ácaros se analizó mediante coeficiente de correlación de Pearson.

\section{Resultados y discusión}

Se recolectaron 1548 ácaros adultos en condiciones de malla sombra y 1314 ácaros en condiciones de campo abierto. Del total de ácaros recolectados, $71.5 \%$ corresponde a la especie T. urticae Koch, $15.3 \%$ a $P$. pallidus Banks y $13.2 \%$ a $P$. latus Banks. En campo abierto, la distribución de especímenes en T. urticae para los estratos superior, medio e inferior fue de 528, 434 y 96 , respectivamente, mientras que para $P$. latus fue 282, 253 y 48 recolectas, respectivamente, en condiciones de malla sombra la distribución de T. urticae fue de 584, 348 y 56 especímenes, respectivamente, para $P$. latus la distribución de especímenes por estrato fue de 3, 81 y 37, respectivamente, a su vez, la distribución $P$. pallidus fue de 57, 279 y 103 ejemplares, respectivamente (Cuadro 1). 
Cuadro 1. Ácaros asociados al cultivo de jitomate en los sistemas de producción malla sombra y campo abierto en el norte de Sinaloa, México.

\begin{tabular}{|c|c|c|c|c|c|}
\hline Sitios de muestreo & Familia & Género & Especie & Individuos & Estrato \\
\hline \multirow[t]{6}{*}{ Agrícola Meza } & Tetranychidae & Tetranychus & urticae & 368 & Superior \\
\hline & & & & 125 & Medio \\
\hline & & & & 37 & Inferior \\
\hline & Tarsonemidae & Phytonemus & pallidus & 57 & Superior \\
\hline & & & & 279 & Medio \\
\hline & & & & 103 & Inferior \\
\hline \multirow[t]{6}{*}{ Agrícola Los Reyes } & Tetranychidae & Tetranychus & urticae & 282 & Superior \\
\hline & & & & 253 & Medio \\
\hline & & & & 48 & Inferior \\
\hline & Tarsonemidae & Polyphagotarsonemus & latus & 62 & Superior \\
\hline & & & & 104 & Medio \\
\hline & & & & 90 & Inferior \\
\hline \multirow[t]{3}{*}{ Agrícola San José } & Tetranychidae & Tetranychus & urticae & 246 & Superior \\
\hline & & & & 181 & Medio \\
\hline & & & & 45 & Inferior \\
\hline \multirow[t]{6}{*}{ Agrícola Moreno } & Tetranychidae & Tetranychus & urticae & 216 & Superior \\
\hline & & & & 223 & Medio \\
\hline & & & & 19 & Inferior \\
\hline & Tarsonemidae & Polyphagotarsonemus & latus & 3 & Superior \\
\hline & & & & 81 & Medio \\
\hline & & & & 37 & Inferior \\
\hline
\end{tabular}

Los resultados del análisis de correlación se muestran en el Cuadro 2. Se observó que la precipitación solo estuvo asociada con las poblaciones de T. urticae en dos sitios, Agrícola Moreno y Agrícola San José, mientras que la densidad poblacional de las especies observadas se encuentra altamente relacionada con las temperaturas, en coincidencia con Solano et al. (2008) en cuanto a fluctuación poblacional de Brevipalpus spp., la cual es directamente proporcional al aumento de la temperatura, al oscilar entre 24 y $33{ }^{\circ} \mathrm{C}$ favorecen el desarrollo poblacional.

Cuadro 2. Coeficiente de correlación (Pearson) entre precipitación y temperaturas con densidad poblacional de $\boldsymbol{T}$. urticae, $P$. latus y $P$. pallidus en el norte de Sinaloa, México.

\begin{tabular}{cccccc}
\hline Sitios & Especie & Precipitación & $\begin{array}{c}\text { Temperatura } \\
\text { máxima }\end{array}$ & $\begin{array}{c}\text { Temperatura } \\
\text { mínima }\end{array}$ & $\begin{array}{c}\text { Temperatura } \\
\text { media }\end{array}$ \\
\hline A. Los Reyes & T. urticae & 0.13737 & 0.7144 & 0.64055 & 0.70875 \\
& & 0.6871 & 0.0135 & 0.0337 & 0.0146 \\
& P. latus & 0.10315 & 0.87177 & 0.71804 & 0.84535 \\
& & 0.7628 & 0.0005 & 0.0128 & 0.001 \\
\hline
\end{tabular}




\begin{tabular}{cccccc}
\hline \multirow{2}{*}{ Sitios } & Especie & Precipitación & $\begin{array}{c}\text { Temperatura } \\
\text { máxima }\end{array}$ & $\begin{array}{c}\text { Temperatura } \\
\text { mínima }\end{array}$ & $\begin{array}{c}\text { Temperatura } \\
\text { media }\end{array}$ \\
\hline A. Moreno & T. urticae & -0.67077 & 0.82448 & 0.77311 & 0.80933 \\
& \multirow{3}{*}{ P. latus } & 0.46193 & 0.64427 & 0.63595 & 0.64694 \\
& & 0.1526 & 0.0324 & 0.0354 & 0.0314 \\
A. San José & T. urticae & -0.63687 & 0.93362 & 0.90595 & 0.93099 \\
& & 0.0351 & $<0.0001$ & 0.0001 & $<0.0001$ \\
A. Meza & T. urticae & -0.23932 & 0.76043 & 0.78211 & 0.78605 \\
& & 0.4785 & 0.0066 & 0.0044 & 0.0041 \\
& \multirow{3}{*}{ P. pallidus } & -0.18814 & 0.77319 & 0.64699 & 0.74097 \\
& & 0.5796 & 0.0053 & 0.0314 & 0.0091 \\
\hline
\end{tabular}

Coeficiente de correlación (CC) Prob > IRl; ${ }^{*}=$ las variables están correlacionadas $(\alpha=0.05)$.

En Agrícola Meza, en condiciones de malla sombra, se recolectaron 530 individuos de T. urticae y 439 de $P$. pallidus. La presencia de T. urticae se registró en los estratos medio y superior de las plantas; las mayores densidades poblacionales se presentaron en abril y mayo, por coincidir con las condiciones ideales (Aucejo-Romero, 2005), que provocaron que las hojas se cubrieran completamente de telaraña, debido a que el agricultor no realizó las medidas fitosanitarias dado los bajos precios del jitomate en el mercado.

La especie $P$. pallidus (Figura 1 y 2), prefirió el estrato medio de la planta, por preferir hábitats oscuros y húmedos (DGSV-CNRF, 2014) y su fluctuación varió dentro del cultivo, con diferentes picos poblacionales con presencia durante los meses de febrero a mayo, con condiciones favorables de temperatura (Cloyd, 2010).

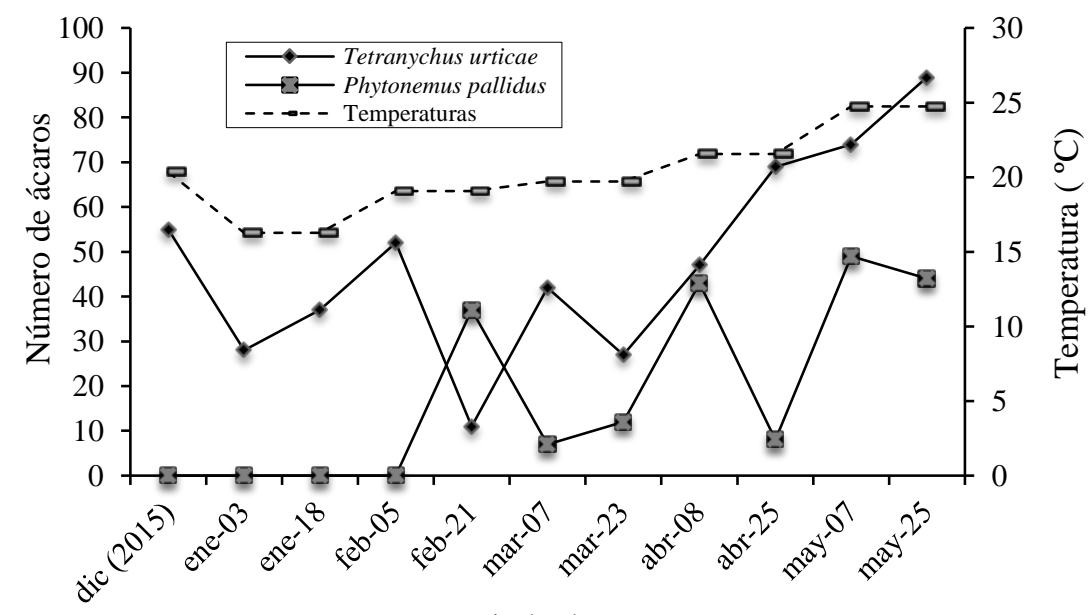

Periodo de muestreo

Figura 1. Fluctuación poblacional de ácaros en jitomate bajo condiciones de malla sombra, Agrícola Meza. 


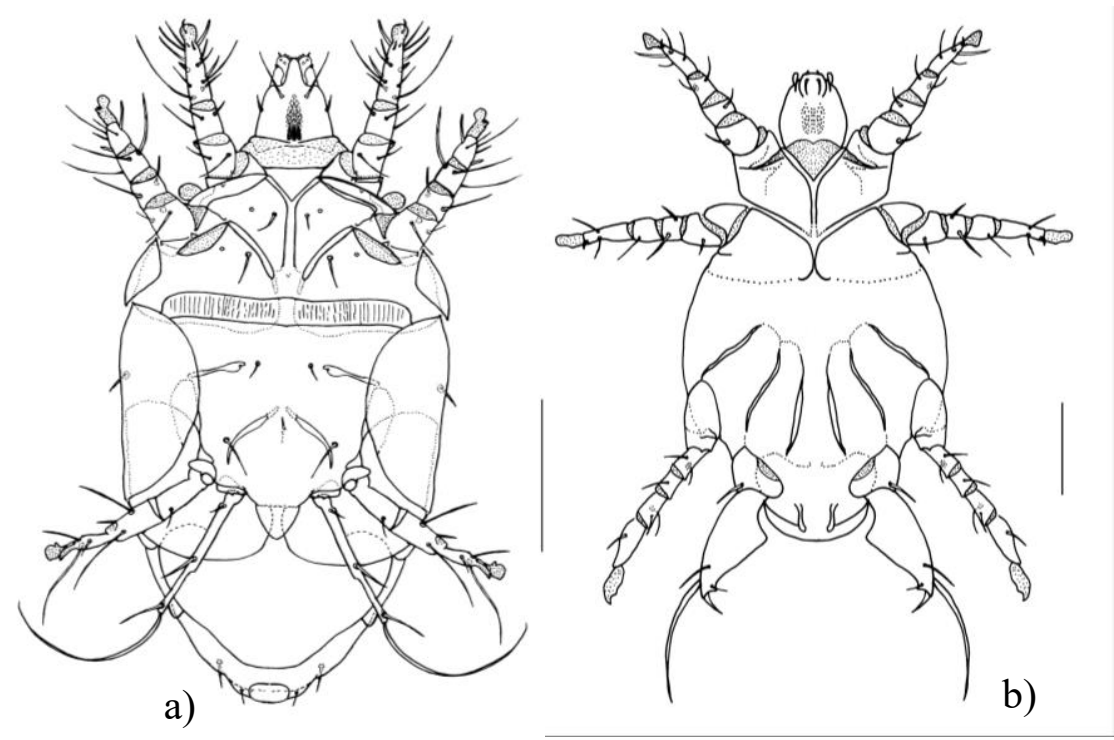

Figura 2. Vista ventral de adulto de Phytonemus pallidus. a) hembra; y b) macho. Escala $100 \mu \mathrm{m}$.

Para el sistema de campo abierto en Agrícola Los Reyes (Figura 3), se recolectó un total de 839 ácaros, de los cuales 583 corresponden a $T$. urticae y 256 a P. latus. Las poblaciones más altas de $T$. urticae se presentaron en mayo, en coincidencia con los incrementos de temperaturas; esta especie prefiere los estratos medio y superior de la planta.

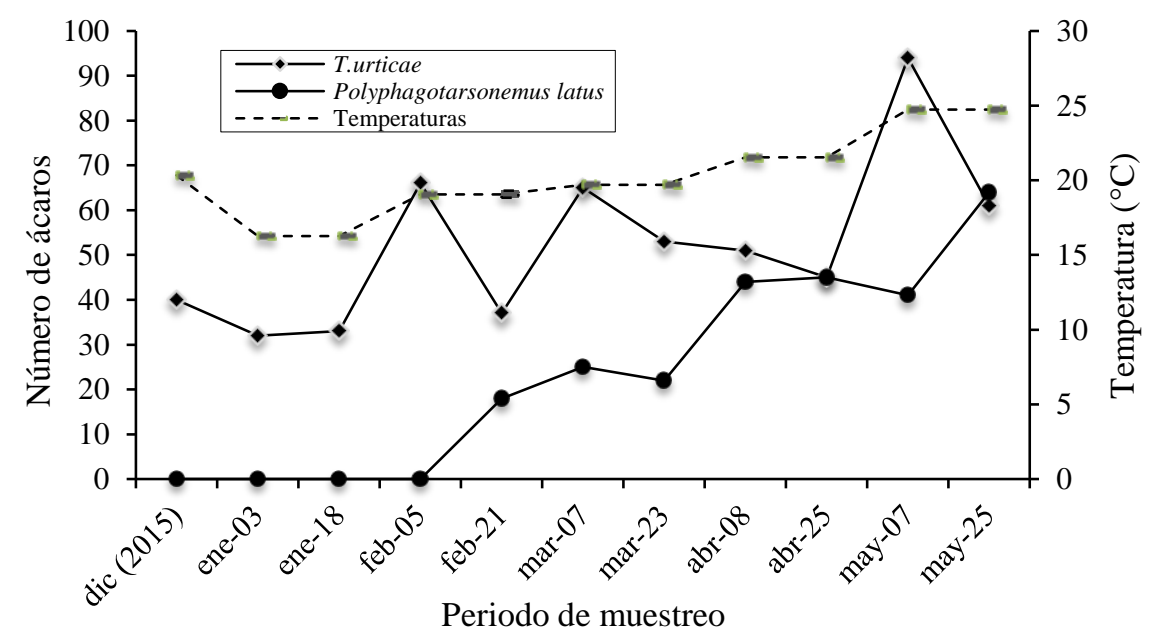

Figura 3. Fluctuación poblacional de $T$. urticae y $P$. latus en jitomate de campo abierto en Agrícola Los Reyes.

Los resultados obtenidos indican que existe una relación entre la temperatura y población de ácaros, lo que coincide con Da Silva (2002); Prasliĉka y Huszár (2004), quienes sostienen que los veranos calientes y secos favorecen la reproducción de los ácaros. La especie $P$. latus se recolectó en febrero e incrementó su población en abril y mayo, donde mostró preferencia por los estratos medio e inferior de las plantas, ya que son lugares húmedos, sombríos y estos ácaros se alimentan de la superficie inferior de la hoja (Peña y Bullock, 1994). 
En Agrícola San José (Figura 4) se recolectaron 475 individuos de T. urticae en jitomate establecido sistema de producción a campo abierto, cuya presencia se ubicó en los estratos medio y alto de la planta, siendo la única especie encontrada en este sitio; asimismo, su presencia se registró desde los primeros muestreos, el cual mantuvo su población de febrero a mayo y fluctúo de acuerdo a las altas temperaturas que oscilaron de 20 a $30{ }^{\circ} \mathrm{C}$, favorables para su desarrollo y ciclo biológico, lo mismo que de baja humedad relativa y presencia de algunos insectos depredadores como Stethorus sp. (Coleoptera: Coccinallidae), registrados en el estudio.

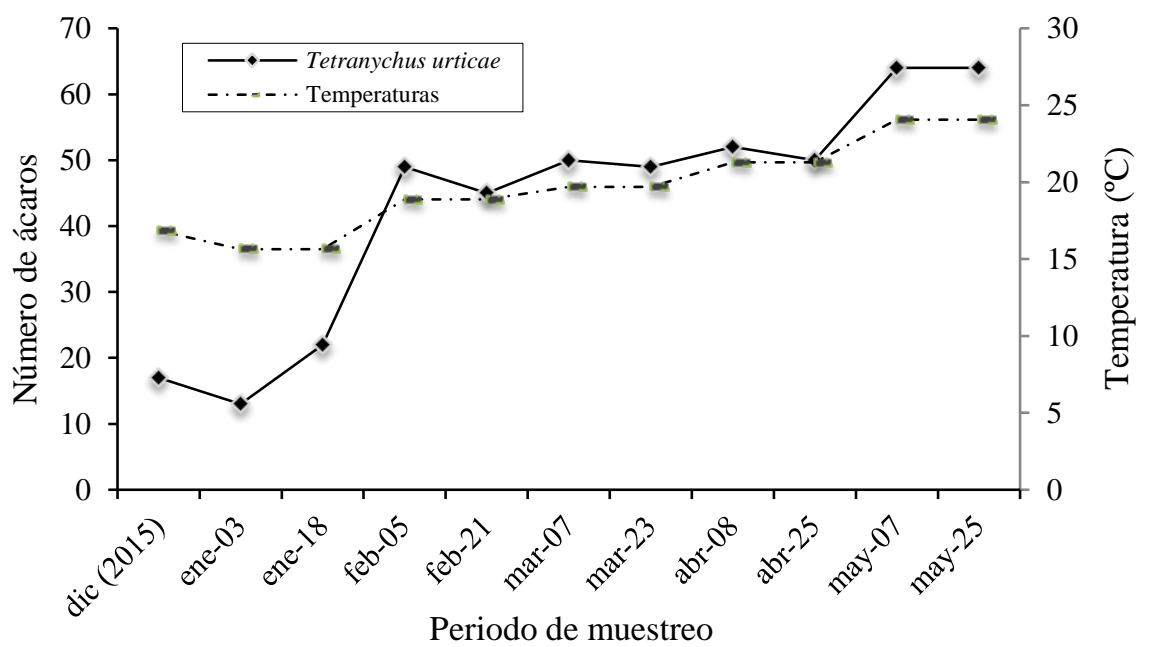

Figura 4. Fluctuación poblacional de T. urticae en jitomate de campo abierto en Agrícola San José.

En Agrícola Moreno bajo condiciones de malla sombra, se obtuvo un total de 579 especímenes, de los cuales, 458 correspondieron a $T$. urticae y 121 a P. latus (Figura 5). La especie T. urticae se presentó desde el primer muestreo en diciembre 2015 con bajas poblaciones durante los primeros meses, con los mayores picos poblacionales en abril y mayo de 2016, esta especie se ubicó alimentándose con mayor preferencia en las partes media y alta de las plantas. La especie P. latus se encontró en la parte inferior de la planta en febrero y elevó sus poblaciones en abril y mayo, hasta el final del cultivo presentó el mayor número de individuos en la parte media de la planta.

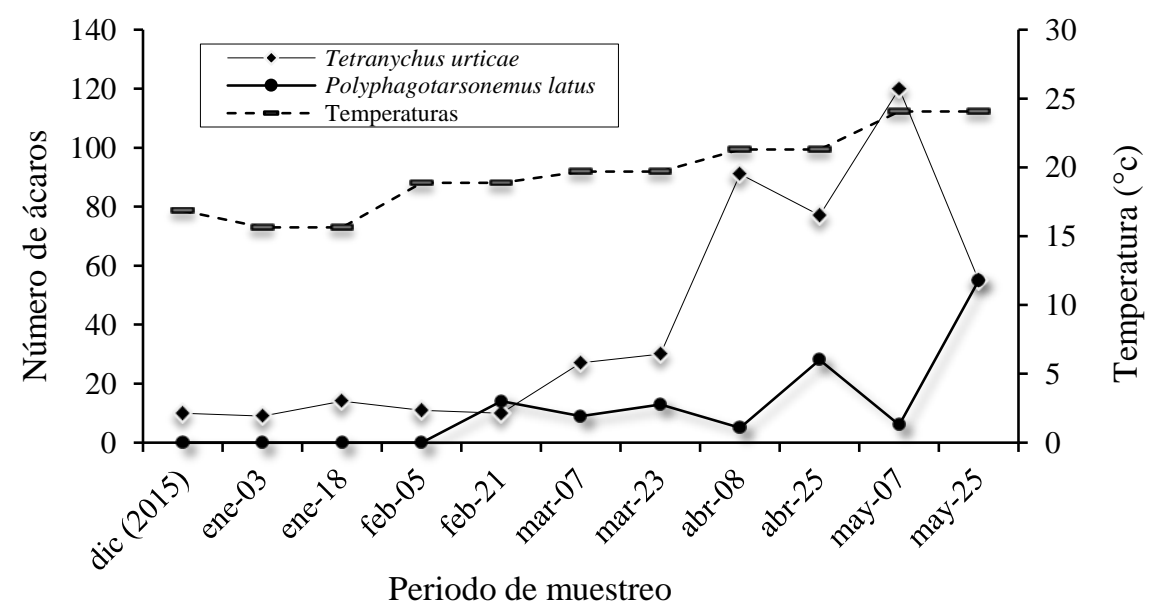

Figura 5. Fluctuación poblacional de $T$. urticae y $P$. latus en jitomate bajo condiciones de sombra en Agrícola Moreno. 
Cabe señalar, que el porcentaje de ácaros fitófagos asociados al cultivo de jitomate en el norte de Sinaloa (Figura 6) es mucho mayor en comparación al número de ácaros depredadores y comensalistas, algunos resultado que coincide con lo obtenido indican que (Oligonychus punicae Tutle) y (Olygonychus perseae Hirst) (Tetranychidae), son las especies de ácaros fitófagos más representativas y dañinas en el cultivo de aguacate (Persea americana Mill, 1768) en Michoacán dependen también del manejo agronómico del cultivo, es determinante en el número de ácaros presente en cada lote y en cada muestreo.

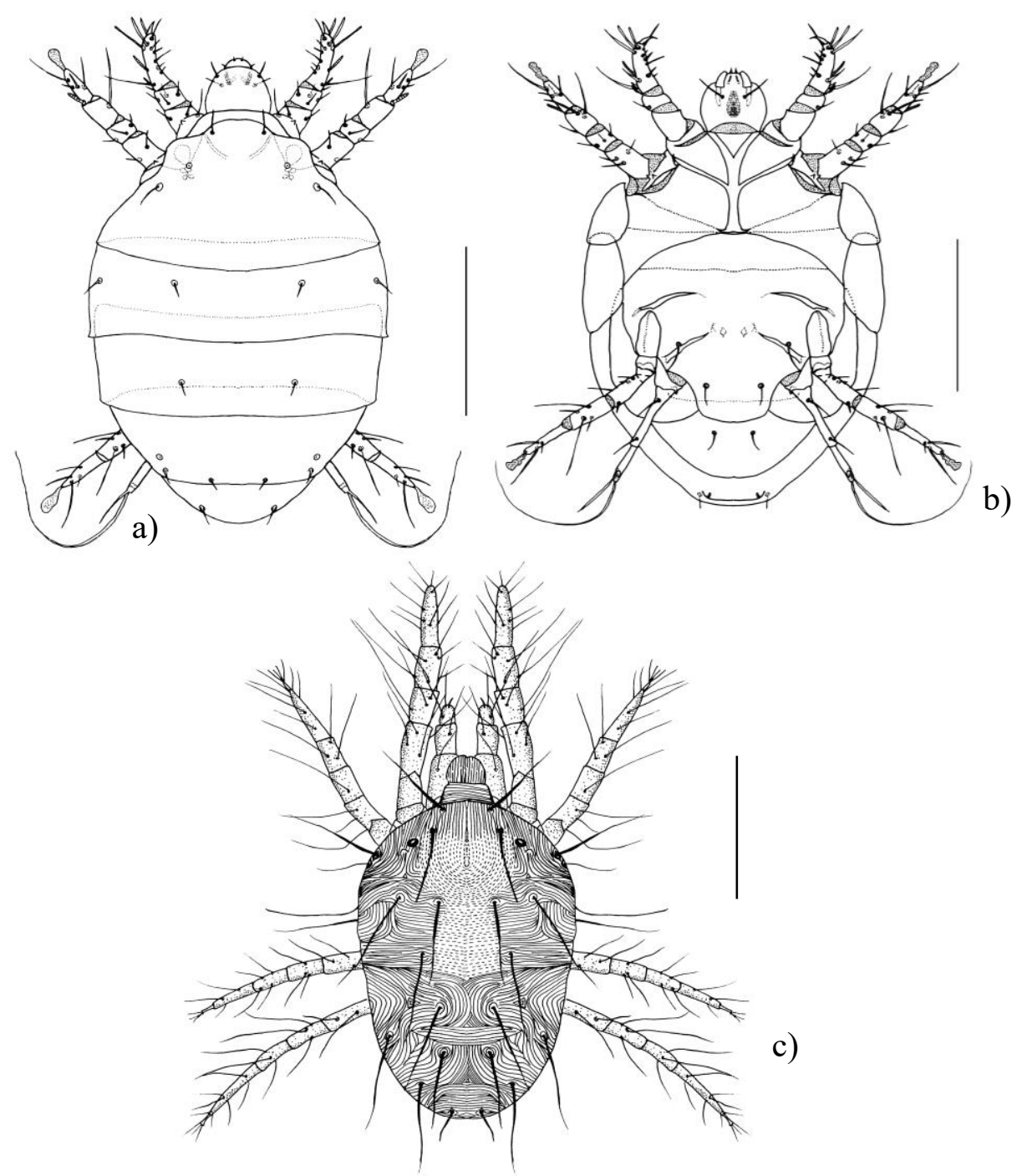

Figura 6. a) Vista dorsal de macho de Polyphagotarsonemus latus. b) vista ventral de hembra de $P$. latus y c) vista dorsal de macho de Tetranichus urticae. Escala $100 \mu \mathrm{m}$.

Lo cual coincide con los resultados obtenidos en esta investigación, toda vez que los lotes que mostraron mayor deficiencia en el manejo agronómico del jitomate presentaron mayor abundancia de ácaros y por lo tanto, mayor daño (Chow et al., 2009; Flores et al., 2011). Es importante señalar que al final del ciclo del cultivo la especie que presentó el menor porcentaje de incidencia poblacional fue $P$. pallidus $(84 \%)$ y las agrícolas Meza y Moreno presentaron valores intermedios con $(57$ y $60 \%)$, respectivamente. 
En Agrícola Los Reyes y Agrícola San José se evidenció la incidencia de ácaros en campo abierto, desde 22 hasta $37 \%$, en contraste bajo condiciones de malla sombra que muestran la incidencia de ácaros en los dos sistemas de producción, la presencia de mayor incidencia se presentó ya que las temperaturas fueron favorables para el desarrollo del ácaro.

\section{Conclusiones}

Se determinó a $T$. urticae Koch, $P$. latus Banks y P. pallidus Banks, como las especies de ácaros fitófagas asociadas al cultivo de jitomate en los diferentes sistemas de producción en el norte de Sinaloa, las cuales tienen un gran potencial en el impacto del daño sobre las hojas tiernas y los frutos. Durante el desarrollo del cultivo T. urticae estuvo presente durante todas las etapas presentado su más baja población en enero, febrero y su mayor incidencia en abril y mayo respectivamente, lo cual está relacionado con la temperatura.

La especie $P$. latus Banks se encontró en el cultivo de jitomate en las etapas de floración y fructificación y a $P$. pallidus Banks estuvo presente en malla sombra durante la etapa reproductiva del cultivo.

\section{Literatura citada}

Aucejo-Romero, S. 2005. Manejo Integrado de Tetranychus urticae Koch (Acari: Tetranychidae) en clementinos: agregación, dinámica e influencia del estado nutricional de la planta huésped. Tesis Doctoral, Universidad Politécnica de Valencia.

Bautista, Z.; Delfín, H. G. H. y Palacio-Prieto, J. L. 2004. Técnicas de muestreo para manejadores de recursos naturales. Instituto de Ecología-Instituto de Geografía UNAM-UAY. 507 p.

Cloyd, R. A. 2010. Broad mite and cyclamen mite: management in greenhouses and nurseries. Kansas State University. 4 p.

Chow, A.; Chau, A. and Heinz, K. M. 2009. Reducing fertilization for cut roses: effect on crop productivity and twospotted spider mite abundance, distribution, and management. J. Econ. Entomol. 102(5):1896-1907.

Da Silva, C. 2002. Biología e exigencias térmicas do ácaro-vermelho (Tetranychus ludeni Zacher) em folhas de algodoeiro. Pesquisa Agropecuária Brasileira. 37(5):573-580.

DGSV-CNRF. 2014. Ácaro del ciclamen, Phytonemus pallidus (Banks). Dirección General de Sanidad Vegetal- Centro Nacional de Referencia Fitosanitaria. Ficha técnica. México, DF. $13 \mathrm{p}$.

Evans, G. O. 1992. Principles of acarology. CAB International. 563 p.

Fasulo, T. R. 2000. Two spotted spider mites. Publication number EENY-150. University of Florida. http://entnemdept.ufl.edu.

Flores, C. R. J.; Mendoza, V. R.; Landeros, F. J.; Cerna, C. E.; Robles, B. A. e Isiordia, A. N. 2011. Caracteres morfológicos y bioquímicos de Rosa x hybrida contra Tetranychus urticae Koch en invernadero. Rev. Mex. Cienc. Agríc. 3:473-482.

Hoffmann, A. y López-Campos, G. 2000. Biodiversidad de los ácaros en México. Comisión Nacional para el Conocimiento y Uso de la Biodiversidad (CONABIO). México, DF. $230 \mathrm{p}$. 
Jaramillo, J.; Rodríguez, V. P.; Guzmán, M.; Zapata, M. y Rengifo, T. 2007. Manual técnico de buenas prácticas agrícolas (BPA) bajo condiciones protegidas en la producción de jitomate. Medellín. Colombia. 331 p.

Jeppson, L. R.; Keifer, H. H. and Baker, H. W. 1975. Mites injurious to economic plants. University of California Press, Berkeley. Los Angeles, USA. 614 p.

Krantz, G. W. 1978. A manual of acarology. Oregon State University Book Stores, Inc. Corvallis, Oregon. 509 p.

Krantz, G. W. and Walter, D. E. 2009. A manual of acarology. Third Edition. Texas Tech University Press. Lubbock, Texas. 807 p.

Nuño-Moreno, R. 2007. Manual de producción de jitomate rojo bajo condiciones de invernadero para el Valle de Mexicali, Baja California. México. 26 p.

Peña, J. E. and Bullock, R. C. 1994. Effects of broad mite, Polyphagotarsonemus latus feeding on vegetative plant growth. Florida Entomologist. 77(1):180-184.

Pérez, T. M.; Guzmán-Cornejo, C.; Montiel-Parra, G.; Paredes-León, R. y Rivas, G. 2013. Biodiversidad de ácaros en México. Departamento de Zoología-Universidad Autónoma de México (UNAM). México, DF Rev. Mex. Biod. 84:399-407.

Praslicka, J. and Huszár, J. 2004. Influence of temperature and host plants on the development and fecundity of the spider mite Tetranychus urticae (Acarina: Tetranychidae). Plant Protection Sci. 40(4):141-144.

Rabinovich, J. E. 1980. Introducción a la ecología de poblaciones de animales. CECSA. México, $313 \mathrm{p}$.

SAGARPA. 2014. Secretaría de Agricultura, Ganadería, Desarrollo Rural, Pesca y Alimentación. Comunicado de prensa. http://www.sagarpa.gob.mx/saladeprensa/2014/paginas /2014B615.aspx.

Sánchez-Peña, P. K.; Oyama, J.; Núñez-Farfán, J.; Fornoni, S.; Hernández-Verdugo, J. y GarzónTiznado J. A. 2006. Sources of resistance of whitefly (Bemisia spp.) in wild populations of Solanum lycopersicum var. cerasiforme (Dunal) Spooner, G.; Anderson, J. and Jansen, R. K. in Northwestern Mexico. Genetic Resources and Crop Evolution. 53(4):711-719.

SIAP. 2016. Servicio de Información Agroalimentaria y Pesquera. http://www.siap.sagarpa.gob.mx/.

Solano, D. A.; Álvarez, J. G. y Rodríguez, J. A. 2008. Distribución espacial de Brevipalpus phoenicis, vector de la leprosis de los cítricos en el cultivo de naranja valencia (Citrus sinenesis) en Yopal, Casanare (Colombia). Agron. Colomb. 26(3):399-410.

Tuttle, D. M.; Baker, E. W. and Abbatiello, M. 1974. Spider mites from northwestern and north central México (Acarina: Tetranychidae). Smithsonian Contributions to Zoology. 171:1-18.

Zhang, Z. Q. 2003. Mites of greenhouses. Identification, Biology and Control. CABI Publishing. (Eds). 235 p.

Zhang, Z. Q. 2011. Phylum Arthropoda von Siebold, 1848. In: animal biodiversity: an outline of higher-level classification and survey of taxonomic richness, Z. Q. Zhang (Ed.). Zootaxa. 3148(Special issue):99-103. 